\title{
Efectos del programa Usura Cero en el desarrollo económico de MIPYMES en Estelí 1
}

\author{
Ana Yansis Rodríguez Lanuza ${ }^{2}$ \\ Ruth Yamali Herrera Lanzas ${ }^{3}$ \\ Suyapa Massiel Baldelomar Portillo ${ }^{4}$
}

\begin{abstract}
1 Este artículo se basa en la investigación titulada Efectos del programa Usura Cero en el desarrollo económico de MIPYMES en Estelí. Para obtener el título de Licenciado en Administración de Empresas de la UNAN-Managua, FAREMEstelí.

2 UNAN-Managua FAREM-Estelí, Correro electrónico: ay_rodriguez03@yahoo.com

3 UNAN-Managua FAREM-Estelí, Correro electrónico: ryamali_top@hotmail.com

4 UNAN-Managua FAREM-Estelí, Correro electrónico: massielbaldelomar@yahoo.com
\end{abstract}

\section{RESUMEN}

Esta investigación evalúa los efectos del Programa Usura Cero en el desarrollo económico de las MIPYMES creadas por la beneficiadas con el crédito en la ciudad de Estelí en el año 2013 y donde se propondrán estrategias para el fortalecimiento de las mismas. El enfoque de la investigación es cuantitativo. Se aplicaron entrevistas y encuestas para brindar veracidad a la información brindada en el documento.

Según la problemática encontrada el programa ha beneficiado en gran cantidad los negocios de las mujeres pues en la actualidad los pequeños negocios se enfrentan con barreras para el acceso a financiamiento en especial cuando no pueden presentar pruebas de ingresos estables; además en la sociedad que vivimos la mujer recibe menos apoyo que el hombre para emprender un negocio también accede más difícilmente al crédito que ofrecen las entidades financieras.

Se recomienda la incorporación de libros de ingresos y egresos, atraer nuevos clientes para mejorar su posición en el mercado, utilizar el crédito únicamente para la inversión en el negocio y ampliar su visión empresarial para reducir las debilidades y potenciar las fortalezas y oportunidades, que logren conducir al desarrollo de las MIPYMES.

Palabras clave: MIPYMES, Crédito, Programas Sociales, Desarrollo. 


\title{
Effects of zero usury program in economic development in the MIPYMES of Estelí
}

\author{
Ana Yansis Rodríguez Lanuza² \\ Ruth Yamali Herrera Lanzas ${ }^{3}$ \\ Suyapa Massiel Baldelomar Portillo ${ }^{4}$
}

1 This article is based on the research titled Effects of zero usury program in economic development in the MIPYMES of Estelí. To obtain the title of Bachelor of Business Administration from the UNAN-Managua, FAREM-Estelí.

2 UNAN-Managua FAREM-Estelí, E-mail: ay_rodriguez03@yahoo.com

3 UNAN-Managua FAREM-Estelí, E-mail: ryamali_top@hotmail.com

4 UNAN-Managua FAREM-Estelí, E-mail: massielbaldelomar@yahoo.com

\begin{abstract}
This research evaluates the effects of Zero Usury program in economic development of MIPYMEs created by the beneficiaries of the credit in the city of Estelí in 2013 and where strategies for strengthening them will be proposed. The research approach is quantitative. Interviews and surveys were used to provide the veracity of the information given on the document.

According to the problem found, the program has benefited a great number of women business at present because small businesses face barriers to access to financing especially when they cannot provide evidence of stable income; also the society we live women receive less support than men to start a business also it is harder to access credit that financial institutions offer.

It is recommended to incorporate the income and expenditure books, attract new customers to improve their market position, use credit only for investment in the business and expand their business vision to reduce the weaknesses and enhancing the strengths and opportunities, achieve lead to the development of MIPYMEs.
\end{abstract}

Keywords: MIPYMEs, Credit, Social Programs Development. 


\section{INTRODUCCIÓN}

En Nicaragua se solicitan créditos a micro financieras por distintas razones, ya sea para crear nuevos negocios, hacer una inversión o ampliar el inventario de negocios ya establecidos. Otra razón para solicitar créditos es cubrir deudas que se tienen con otras entidades financieras.

En la actualidad los pequeños negocios se enfrentan con barreras para el acceso a financiamiento en especial cuando no pueden presentar pruebas de ingresos estables, lo que dificulta tener garantía que respalde el crédito. Otra razón es la alta tasa de interés bancario que está fuera del alcance de pago para muchas personas que solicitan créditos.

Las mujeres han optado por obtener financiamiento bajo el programa Usura Cero porque sus intereses no son capitalizables y son del $4 \%$ y $1 \%$ de mantenimiento al valor para un total de $5 \%$ anual sobre el monto, el cual está al alcance del bolsillo de las mujeres que reciben el microcrédito y está por debajo de la tasa de interés bancario cobrado por muchas entidades financieras que normalmente ascienden del $12 \%$ al $32 \%$ anual.

Otra razón muy importante para que las mujeres soliciten el microcrédito del programa Usura Cero es la falta de equidad en el ámbito económico, pues en la sociedad que vivimos la mujer recibe menos apoyo que el hombre para emprender un negocio también accede más difícilmente al crédito que ofrecen las entidades financieras, esto hace a la mujer menos productiva, por consiguiente está en inferiores condiciones y no puede participar en el desarrollo económico dela sociedad en la que se desenvuelve, con costos evidentes para su bienestar individual y económico.

La falta de empleo existente en el país es otro factor que ha motivado a las mujeres a recurrir al microcrédito de Usura Cero para crear un negocio que sirva como fuente de desarrollo tanto personal como familiar.

La dependencia económica de la mujer es un grave problema que aún no se resuelve pero que se está trabajando en el programa Usura Cero, para que las mujeres tengan independencia económica. Hay limitaciones de toda índole para la mujer pues está sometida a su pareja o a cualquier otra persona, esto se agrava al no contar con una fuente de ingresos propia y vuelve a las familias más vulnerables de caer en pobreza extrema y en el caso de que las mujeres se ven obligadas a asumir solas el cuido y mantenimiento del hogar es de suma importancia que logren la independencia.

La administración no adecuada dificulta tener un control de ingresos y egresos del negocio, al no conocer con exactitud el balance exacto de las cuentas, esta persona se sobregira y enfrenta problemas con el pago del crédito y se ven obligados a buscar otras formas de ingresos para cubrir la cuota.

Las situaciones por las cuales no se puede pagar el crédito traen consigo sobreendeudamiento, por lo tanto no se puede cumplir con la responsabilidad adquirida.

Una de las limitantes para poder ampliar el negocio es que los montos del crédito que reciben las mujeres son bajos, lo cual les dificulta comprar la suficiente materia prima para abastecer el negocio, las mujeres deben escoger bien a sus proveedores porque algunos tienen precios en los productos que no son convenientes para su compra.

Por esto, el Gobierno de Reconciliación y Unidad Nacional teniendo como eje central de sus políticas, el combate a la pobreza ha emprendido el programa de microcrédito "Usura Cero", el cual se orienta exclusivamente a mujeres en extrema pobreza, con el objetivo de apoyar en el emprendimiento de 
pequeños negocios o bien para que puedan fortalecer los negocios que han venido impulsando. El propósito fundamental del Programa Social Usura Cero es crear oportunidades para que mujeres organizadas en grupos solidarios puedan beneficiarse con préstamos para mejorar sus pequeños negocios o puedan emprender uno nuevo; los objetivos de este son Erradicar la Pobreza extrema y el hambre cuya meta es reducir a la mitad entre 1990 y 2015, el porcentaje de personas cuyos ingresos sean Inferiores a 1 dólar por día y Promover la igualdad de género y el empoderamiento de la mujer, a través de proveer los recursos para que las mujeres puedan tener autonomía tanto a nivel personal, familiar como empresarial.

El buen funcionamiento del programa depende en gran parte de las capacitaciones que se imparte a las mujeres beneficiadas con el micro crédito para esto existe un convenio de colaboración entre INATEC y el Programa Usura Cero, este convenio consiste en que el Programa Usura Cero atiende lo que es la parte de crédito y en este caso el responsable de capacitación es uno de los centros el Instituto Politécnico Francisco Rivera Quintero "el Zorro". El grupo técnico de Capacitación está conformado por jóvenes que prácticamente son voluntarios pues no reciben un salario como tal, sino que se les entregan viáticos y capacitaciones para que tengan conocimiento de los distintos temas que se les abordaran a las mujeres

El presente trabajo investigativo tiene como objetivo determinar los efectos que ha tenido el Programa Social Usura Cero en el desarrollo económico de las MIPYMES de la ciudad de Estelí en el año 2013. La realización de este estudio beneficiará a mujeres propietarias de MIPYMES pues aportará información para que empleen nuevas técnicas administrativas para el desarrollo de sus negocios, además motivará a las mujeres a ampliar y diversificar sus negocios con el propósito de mejorar su nivel de vida, así mismo el personal que dirige el Programa Usura
Cero se beneficiará con la información recopilada en este documento, pues estarán al tanto de cómo las propietarias de negocios han evolucionado y en que destinan el capital del préstamo, además servirá para conocer cuáles son la debilidades de los negocios de las mujeres y así fortalecerlos haciendo uso de las estrategias planteadas en el documento.

\section{MATERIALES Y MÉTODOS}

Para llevar a cabo el estudio "Efectos del Programa Usura Cero en el desarrollo económico de las MIPYMES creadas con las mujeres beneficiadas con el programa en la ciudad de Estelí en el año 2013" se utilizaron fuentes primarias de carácter cuantitativo cuyo instrumento fueron encuestas aplicadas a las propietarias de negocios donde se extrajo información acerca de la rentabilidad de los negocios, la administración y contabilidad del mismo, valoración del Programa Usura Cero, entre otros temas y de carácter cualitativo cuyo instrumento fueron entrevistas aplicadas a Licenciada Teresa Cruz responsable del Programa Usura Cero en Estelí, Gustavo Chavarría responsable de capacitación, Leandro Rosales técnico-capacitador y a diez mujeres integrantes del programa en la ciudad de Estelí. También se hizo una revisión bibliográfica de diferentes libros y trabajos de curso para enriquecer y dar veracidad a la información obtenida durante esta investigación.

\section{RESULTADOS Y DISCUSIÓN}

\section{Descripción del programa Usura Cero}

El Gobierno de Reconciliación y Unidad Nacional teniendo como eje central de sus políticas, el combate a la pobreza ha emprendido el programa de micro crédito “Usura Cero", el cual se orienta exclusivamente a mujeres en extrema pobreza, con el objetivo de apoyar en el emprendimiento de pequeños negocios o bien para que puedan fortalecer los negocios que han venido impulsando. 
Para desarrollar las acciones fue conformado el 2 de agosto del 2007 mediante Decreto presidencial No. 75-2007 el consejo nacional del poder ciudadano para el Programa Usura Cero, publicándose una modificación al mismo el 29 de febrero del año 2008 mediante Decreto presidencial No 7-2008, donde se establece que dicho consejo será coordinado por la secretaría de comunicación y ciudadanía de la presidencia asimismo se implementó la unidad técnica del programa, dependiendo administrativamente del ministerio de fomento, industria y comercio.

El consejo nacional del poder ciudadano para el programa usura cero, en cumplimiento a la ley 640 "Ley creadora del Banco de fomento a la producción (produzcamos)", así como el Decreto 432009, autorizo al Ministerio de Fomento, Industria y Comercio (MIFIC) en el acta No.7, de fecha 18 de septiembre del 2009, el traslado de los fondos que tenía asignados para el programa usura cero hacia el Banco Produzcamos, también los bienes muebles utilizados para la operatividad del programa.

Por otra parte y como parte del proceso de traslado, fue suscrito un convenio Inter-Institucional entre el MIFIC y Financiera Nicaragüense de Inversiones (FNI S.A), hoy Banco Produzcamos, donde se formaliza el traslado de fondos y cartera de crédito, comprometiéndose la FNI en la cláusula segunda de dicho documento, entre otras cosas a: "cumplir y hacer cumplir la política de crédito del programa Usura Cero, conforme a lo establecido en su reglamento y manual operativo".

Durante ese traspaso, la unidad técnica del programa se trasladada al Banco produzcamos, dependiendo de la gerencia general de esta institución. Desde que se realizó ese traslado no se han presentado cambios en la política de crédito, así como en su reglamento operativo y manual de funciones, atendiendo hasta el 30 de abril del 2013 a 151,524 socias, de las cuales 36,245 tienen cuatro y más créditos, lo cual representa el $23.9 \%$.
Estas socias han venido planteando la necesidad de aumentar el financiamiento para continuar desarrollando sus pequeños negocios y contribuir de esta manera con la mejoría en la vida de su familia, su comunidad y por consiguiente del país.

Por otra parte, el programa ha continuado trabajando con los equipos departamentales que se han conformado y la cartera está administrada por el Banco Produzcamos, avanzando en la implementación del programa. De tal manera que al 30 de abril se han otorgado 380,969 créditos en 3,843 barrios de 146 municipios del país.

Considerando los avances que se han presentado y el planteamiento de las socias que tienen cuatro y más créditos, se ha considerado necesario revisar las políticas de crédito del programa de tal manera que a partir de mayo 2013 se incorporan experiencias que hasta la fecha se han venido presentando y que de esta manera contribuya a fortalecer la atención que se brinda a las socias.

\section{Funcionamiento del programa Usura Cero en la ciudad de Estelí}

El Programa Usura Cero inicia sus funciones en Estelí en el año 2008 con fondos "Alba-Caruna", el Presidente Hugo Chávez hizo un préstamo al gobierno Nicaragüense para que implementara el programa pues tenía altas expectativas del país pese a que en otros países de América Latina se intentó implementar el programa y fracasó, actualmente el préstamo a Venezuela fue cancelado y el fondo que ahora se maneja es propio del gobierno.

"Los fondos fueron "Alba-Caruna" de Venezuela, el Presidente Hugo Chávez dijo al Comandante Daniel Ortega yo te suelto los millones para que lo implementes y dio un plazo de pago, hay gente que creía que esto iba a ser fracaso. Con el fondo, se ha pagado a Venezuela y ahora es propio del gobierno 
y revolvente." (Lic. Teresa Cruz, Responsable del Programa Usura Cero en Estelí)

En el año 2008 se hizo la colocación de 3,000 créditos, en grupos solidarios que ya habían sido conformados por el consejo del poder ciudadano

"Iniciamos con las uñas, solo me dijeron de la dirección del partido, compañera usted asume este cargo y usted tiene que instalarlo, mi función es planificar, dirigir y coordinar todo el programa tengo que manejar todo lo que hay aquí, hasta el último peso, yo reviso, superviso y apruebo todo los créditos." (Lic. Teresa Cruz. Responsable del Programa Usura Cero en la ciudad de Estelí)

En Usura Cero se realiza un trabajo en equipo, sin importar los cargos se ayudan mutuamente para que el programa marche bien, para los trabajadores no es problema salir a recorrer la casa de habitación de las mujeres beneficiadas, estar con la gente viendo los problemas es uno de los factores claves que les ayudana la planificación de sus actividadessean datos concretas, al principio hubo una mala organización de los grupos se encontraron con que habían mujeres que no se conocían dentro de sus mismos grupo, lo que afecto en el año 2008-2009 pues la mora del departamento era de casi un millón de córdobas, hasta la fecha hay una recuperación de más del $50 \%$ de esta mora, el encargado de recuperar este dinero es Caruna, ya que ese fondo lo desembolsaban ellos .Del año 2010 a la fecha el dinero es desembolsado por el Programa Usura Cero con su propios fondos, con estos fondos propios atienden al municipio de Estelí San Nicolás, La Trinidad y Condega.

"Llevamos alrededor de 19 mil créditos sumando el primero, el segundo, tercer créditos o lo que hayan tenido ya las mujeres, tenemos una colocación de 125 millones en todo el departamento y la mora es de $0.6 \%$. Actualmente laboramos 12 personas incluyendo al conserje y el programa seguirá dando frutos porque para eso estamos trabajando. (Lic. Teresa Cruz. Responsable del programa Usura Cero de la Ciudad Estelí.

\section{Funcionamiento de las Capacitaciones}

El buen funcionamiento del programa Usura Cero también depende de las capacitaciones que imparte a las mujeres beneficiadas con el micro crédito para esto existe un convenio de colaboración entre INATEC y el Programa Usura Cero, este convenio consiste en que el Programa Usura Cero atiende lo que es la parte de crédito y en este caso el responsable de capacitación es uno de los centros el Instituto Politécnico Francisco Rivera Quintero "el Zorro".

El grupo técnico de Capacitación está conformado por jóvenes que prácticamente son voluntarios pues no reciben un salario como tal, sino que se les entregan viáticos y capacitaciones para que tengan conocimiento de los distintos temas que se les abordaran a las mujeres.

"Somos jóvenes comprometidos con la revolución, seguimos el mandato del Comandante Daniel Ortega de hablar con las mujeres para que se haga un cambio positivo en sus vidas" (Leandro Rosales. TécnicoCapacitador del Programa Usura Cero)

El equipo técnico, recibe capacitaciones dos veces al año y los responsables se encargan de darle un seguimiento utilizando la metodología de charlas sobre los contenidos de acuerdo con las fases del crédito en la que estén las mujeres.

En la primera fase el contenido que se les habla es como se solicita un crédito en la banca formal para que hagan una comparación de la facilidad que da el programa, asociatividad y cooperativismo para que las mujeres se vallan formando en grupos donde todas las integrantes se conozcan, se les habla de cómo manejar su crédito, que han hecho con sus créditos 
anteriores y como hacer un presupuesto así como temas de administración y contabilidad del negocio.

En la segunda fase se habla de temas como violencia intrafamiliar y de que trata la ley 779 de restitución de derechos que el programa quiere incorporar, por otra parte se aborda el tema contable que es uno de los temas más importantes pues se les instruye a llevar un presupuesto, a invertir lo que se gana y como conocer el beneficio-costo de su negocio, la intensión no es que administren un negocio enorme si no que ellas sepan cuanto es lo que invierten y lo que ganan.

"Nosotros valoramos por vos de ellas misma que los contenidos le han servido por ejemplo en los que es la tema de violencia Intrafamiliar les ha interesado mucho así como también lo que es la parte de Administración y Contabilidad del Negocio, lo ven como una herramienta útil para poder medir en algún sentido cuales son los beneficios del negocios." (Lic. Gustavo Chavarría, Responsable de Capacitaciones I.P- Estelí)

Las capacitaciones son 1 vez a la semana, el día que lo solicitan y el día que les van a entregar el crédito después de ese tiempo ya no reciben capacitaciones hasta que pagan el crédito Semanal se atiende a un promedio de 300 mujeres, hay semanas en las que se atiende alrededor de 500 mujeres para eso se cuenta con un equipo de 9 capacitadores.

\section{Valoración del programa Usura Cero}

\section{Como se conoció del Programa Usura Cero}

Se preguntó a las mujeres sobro como conocieron del Programa Según los datos se refleja que un $53.25 \%$ de ellas conocieron del programa por medio del consejo del poder ciudadano, conocidos como CPC ya que cuando el programa se empezó a implementar ellos desde sus barrio empezaron a realizar la coordinación y organización de los grupos solidarios de mujeres.
El $18.04 \%$ lo conocieron a través de amistades ya que el programa está presente en todo el municipio de Estelí.

Un $15.69 \%$ se enteró del programa por recomendación de las demás compañeras que ya han sido beneficiadas con el programa, un $13.02 \%$ supo del programa por los medio de comunicación ya que los medios le han dado seguimiento a este programa desde que fue impulsado por el gobierno.

\section{Créditos Obtenidos}

Acerca de cuantos créditos han obtenido se refleja que un $58.28 \%$ de las mujeres han recibido de cinco a diez préstamos, llegan a recibir al año dos préstamos ya que el plazo de pago es de ocho meses pero algunas de ellas cancelan el préstamo en seis meses lo que les facilita obtener un segundo préstamo en el año, un $34.02 \%$ han recibido de uno a cinco préstamos pues son grupo recientemente organizados, han ingresado al programa y han obtenido el préstamo,

Un $15.69 \%$ han obtenido de diez a mas préstamos debido a que desde que se implementó el programa Usura Cero en la ciudad ellas han sido parte de este.

Cabe recalcar que los montos de los préstamos varían dependiendo del desarrollo que el negocio presente, los montos van desde 3,700 córdobas, 5,500 córdobas y recientemente hasta 10,000 córdobas. Para poder conocer cuál es el monto que se les va a asignar a las mujeres se realizan inspecciones en sus hogares ya que en algunas ocasiones no se invierte en los negocios la suma total del préstamo y lo utilizan para otros gastos.

"Cuando las compañeras que se encargan de la verificación salen a inspeccionar, Ilenan una hoja donde hacen una valoración del negocio y dependiendo de eso se asigna un monto de crédito por ejemplo si vamos a verificar y en una de las 
pulperías solo tienen tres ristras de meneítos se les asignan 3,700 córdobas porque nos damos cuenta de que esa compañera no está invirtiendo el préstamo para lo que lo solicitó, hay otras compañeras que si lo invierten y a ellas se les da el monto de 5500 córdobas $y$ hay mujeres a las que les entregamos 10,000 córdobas porque esos son negocios, bendecidos, prosperados y en victoria. Negocios que comenzaron con un poquito para su venta y ahora son grandes pulperías, hay compañeras que si destazaban 1 cerdo a la semana ahora destazan hasta 3 por semana" (Lic. Teresa Cruz, Responsable del programa Usura Cero en la ciudad de Estelí)

No obstante las mujeres que reciben el crédito de 10000 córdobas tienen que haber recibido al menos cinco créditos anteriormente, y haber sido inspeccionada para saber que en verdad va invertir el dinero en su negocio, si se tiene más de cinco créditos y el negocio no muestra cambios aunque solicite el monto de 10,000 córdobas, este no será otorgado ya que si no se muestran mejores en el negocio quiere decir que no están invirtiendo el dinero el este.

Actualmente el municipio de Estelí es uno de los mejores a nivel nacional en cuanto a recuperación de cartera, no obstante existen mujeres que no cumplen con el pago completo de sus préstamos en tiempo y forma, esto llega a ser una desventaja para ellas porque mientras estén atrasadas en sus pagos no pueden optar a un siguiente préstamo, esto no significa que las mujeres al retrasarse y caer mora no puedan solicitar otro préstamo, pues al cancelar pueden solicitar un nuevo préstamo y este será aprobado.

"La orden del comandante Daniel Ortega es que mujer que paga, mujer a la que se le da crédito aunque haya quedado mal en el crédito anterior" (Lic. Teresa Cruz, Responsable de programa Usura Cero en la ciudad de Estelí).

\section{Ventajas del Programa Usura Cero}

Sobre las ventajas que se obtienen al ser parte del Programa Usura Cero el $56.80 \%$ de las mujeres consideraron que el programa les ha traído beneficios en cuanto a todas las ventajas antes mencionadas.

El $23.66 \%$ de las mujeres han mejorado sus ingresos familiares con la rentabilidad que han obtenido de sus negocios. $23.07 \%$ de las dueñas de los negocios encuentran ventajoso que el programa Usura Cero imparta capacitaciones ya que estas les transmiten conocimientos que son necesarios poner en práctica en todo negocio para su éxito. El $10.36 \%$ de las mujeres dueñas de negocios han ampliado su negocio a medida que van obteniendo más créditos de parte del programa.

El $7.99 \%$ de las mujeres encuestadas tienen nuevas amistades a partir de la creación de sus negocios porque para ellas esto significa nuevas oportunidades pues se relacionan aún más directamente con las personas lo que hace que surjan lazos de amistad y en ocasiones laborales y el $1.78 \%$ de las propietarias de negocios buscan independencia económica es decir que con las ganancias que les generan sus negocios pueden subsistir.

\section{Desventajas del Programa Usura Cero}

El $53.55 \%$ de las mujeres encuestadas dicen que el monto de préstamo del programa es muy bajo por consiguiente no cubre todas las necesidades de inversión que se tienen en los negocios.

No obstante el $31.65 \%$ de las mujeres expresaron que el Programa Usura Cero no tenía ninguna desventaja. En cuanto al plazo de pago y dificultad para recaudar cuotas no existían inconvenientes según palabras de las mujeres esto se debe a que las cuotas se pagan semanalmente por lo tanto no se les dificulta recaudarlas y el plazo de pago es adecuado para el monto de préstamo que les brindan. 


\section{Continuación en el Programa}

El $99.70 \%$ de las mujeres están dispuestas a continuar en el Programa Usura Cero ya que es de gran ventaja tener un financiamiento con una baja tasa de interés, además recalcaron que es un proyecto que las ha venido beneficiando ya que en años anteriores no habían sido tomada en cuentas y es de gran importancia saber que gobierno les da un apoyo para poder tener un negocio que les ayude a mantener sus hogares y tener un trabajo fijo.

Tan solo una mujer opino no querer seguir en el programa ya que se le presentaban problemas con su grupo, pues al recolectar la cuota algunas no la presentaban o no la entregaban completa, lo que le dificultaba realizar en tiempo y forma el pago de su grupo.

\section{Capacitaciones}

Todas las propietarias de negocios han recibido capacitaciones en las que se abordan temas de interés para las beneficiadas siendo estos de finanzas, administración, presupuesto, entre otros. Por lo que se hace una afirmación sobre el cumplimiento de los objetivos del programa. Ninguna de las mujeres encuestadas expreso no haber recibidocapacitaciones, esto porque al entrar al programa es exigido que todas las beneficiadas reciban capacitación.

$84.43 \%$ de las mujeres en su mayoría dijeron que en las capacitaciones han abordado temas de administración, contabilidad, uso del capital y relaciones humanas. Lo cual es importante para el desarrollo exitoso del negocio. El $25.73 \%$ de las mujeres encuestadas dijeron que han abordado temas sobre administración del negocio lo cual lo consideran importante ya que ha sido una herramienta para hacer crecer el negocio y para manejar los fondos e inversiones que se han hecho. El 15.08\% de las mujeres dijo que han aprendido sobre el manejo del recurso capital este es uno de los temas más importantes ya que les enseñan a hacer presupuestos para el uso del crédito. El $9.6 \%$ de las mujeres abordo que han aprendido sobre contabilidad del negocio sin embargo son pocas las mujeres que usan una contabilidad formal en su negocio una de las causas de esto es que la mayoría de los negocios son pequeños por lo tanto no consideran necesario llevar contabilidad y el $6.8 \%$ de las mujeres ha aprendido sobre relaciones humanas esto en cuanto al trato que se le debe dar a los clientes.

\section{Aplicación de conocimientos}

Se refleja que el $95.86 \%$ de las mujeres ha puesto en práctica lo aprendido en las capacitaciones que han recibido ya que mientras más control y orden lleven en todas las actividades que se realizan tendrán un mejor funcionamiento de este.

El $4.14 \%$ no ha puesto en práctica lo aprendido este porcentaje se debe a que hay una gran parte de negocios que son muy pequeños y sus dueñas no consideran necesario llevar una contabilidad o administración en su negocio.

\section{Caracterización de las MIPYMES}

El $59.4 \%$ de las propietarias de estas empresas se ubican entre las edades de 21 a 30 años (29\%) y de 31 a 40 años (30.47\%). Apenas el 5\% está entre los 18 a 20 años y el $7.99 \%$ son mayores de 51 años. El $37.28 \%$ del universo de estudio tienen un nivel académico de primaria, debido a limitantes económicas. Mientras el $31.07 \%$ tienen secundaria y el $8.58 \%$ de las propietarias optaron por pasar un curso técnico para conocer un poco sobre diferentes temas como Administración, Contabilidad, Operador en caja, etc. El $16.86 \%$ fueron alfabetizadas, no tenían grados académicos pero tuvieron la oportunidad de aprender lo básico para poder llevar sus micro negocios. 
Las propietarias de negocios en su mayoría son solteras representadas por el $59.47 \%$, esto indica que no tienen pareja de ninguna clase o bien son madres solteras que han asumido el rol de padre y madre para sus hijos siendo el pilar de sus hogares, por esta razón han recurrido a invertir en un negocio propio establecidos en sus hogares y ser independientes económicamente. El $21.60 \%$ son casadas, pero han ingresado al Programa Usura Cero por para no ser dependientes de sus esposos o para invertir juntos en un negocio. El $18.93 \%$ están acompañadas o en unión de hecho.

\section{Datos generales de los negocios.}

La mayor parte de los negocios establecidos por las mujeres beneficiadas con el micro crédito del Programa Usura Cero son pulperías con $30.47 \%$, porque son negocios que no requieren grandes conocimientos para su administración y los pueden establecer en su casa de habitación. El $19.82 \%$ se dedican a la comercialización de bisutería y ropa nueva o usada, porque consideran que es un negocio de más diversificación y esto lleva consigo relacionarse con más clientes. El $18.64 \%$ de los negocios son ventas ambulantes que varían desde la venta de ropa, de cosméticos de casas comerciales hasta la venta de comida rápida.

El $9.77 \%$ se dedica a vender comida rápida, $7.10 \%$ se dedica a vender tortillas teniendo una clientela fija y la comodidad de realizar estas labores en sus hogares, el $4.73 \%$ de los negocios son pequeñas panaderías, el $4.14 \%$ son talleres de costura, y el $5.33 \%$ corresponde a mínimas cantidades de negocios que no son muy comunes o repetidos como venta de frutas y verduras, repuestos de motos, venta de muebles, venta de recargas, venta de helados y refrescos, confección de muñecas de tela, etc.

\section{Tiempo de Operar}

El $36.10 \%$ del universo de estudio osea la mayor parte de negocios tienen de 6 a 10 años de operar, esto significa que los negocios están muy bien posicionados en el mercado y por su antigüedad son estables pues si los negocios no generaran las suficientes utilidades no seguirían en pie hoy en día.

$35.50 \%$ de los negocios son un poco más recientes y coinciden con el tiempo de operar del Programa Usura Cero ya que gran parte de estos han surgido por los microcréditos brindados por el programa.

Una mínima parte de los negocios correspondiente al $4.14 \%$ son bastante antiguos y han operado desde hace más de 10 años pues algunos han pasado de generación en generación.

\section{Local del negocio}

El $87.87 \%$ de las propietarias tienen la gran ventaja de que el local donde tienen ubicados sus negocios es propio pues están establecidos en sus casas de habitación lo que las favorece en gran manera porque el $59.47 \%$ de las mujeres son solteras esto significa que entre ellas existen madres solteras y tienen que cuidar a sus hijos.

$10.95 \%$ tienen establecidos sus negocios en un lugar rentado lo que las perjudica porque tienen que pagar por el alquiler del local y por ende disminuyen sus ingresos.

Una mínima parte correspondiente a un $1.18 \%$ de las mujeres tienen sus negocios ubicados en locales de familiares, en algunos casos comentan que sus familiares les cobran una pequeña cantidad para hacer uso del local y en otros casos no pagan a sus familiares pero deben de pagar los servicios básicos que consumen mientras disponen del local.

\section{Motivos para iniciar el negocio}

Se refleja que el principal motivo para iniciar un negocio es tener ingresos esto corresponde $53.25 \%$ de las 338 mujeres encuestadas, el sustento económico de las mujeres depende de las utilidades que dejan sus 
negocios, algunas mujeres antes de iniciar con estos, no tenían fuentes de ingresos pues no laboraban y si lo hacían no les resultaba factible por lo que decidieron generar ingresos por sus propios medios y por ende mejorar el nivel de vida tanto de ellas a nivel personal como el de toda su familia.

$29.58 \%$ de las mujeres buscaban independencia económica al iniciar un negocio propio no porque les faltara sustento en sus hogares sino por aportar un poco más a la economía familiar.

\section{Rentabilidad del negocio}

A la mayoría de las propietarias les ha resultado muy beneficioso haber iniciado su negocio pues esto se refleja al conocer que el $69.23 \%$ de los negocios tienen buena rentabilidad económica porque perciben utilidades suficientes para sustentarse.

El $30.77 \%$ se refirieron a que sus negocios en ocasiones marchaban bien y otras veces decaía pero al menos podían mantener a diario sus hogares. Nadie se refirió a que sus negocios marchaban mal y mucho menos que pensaban en cerrar operaciones.

\section{Empleados en el negocio}

El $91.42 \%$ osea la mayor parte de los negocios son manejados únicamente por sus propietarias, ellas mismas realizan todas las funciones en el negocio y no tienen empleados que laboren para ellas porque son negocios pequeños y no necesitan ayuda además la contratación de personal implicaría la reducción de sus ganancias.

El $6.51 \%$ de las mujeres tienen a una persona trabajando en sus negocios pero la mayoría de estas personas son familiares de la propietaria o en algunos casos de su esposo. El 1.78\% de los negocios son más grandes o son negocios que requieren más trabajo por lo que las propietarias han recurrido a contratar de 2 a 5 personas para facilitarles el manejo del negocio.

\section{Desarrollo económico empresarial}

El $47.92 \%$ de los negocios iniciaron a operar con capital propio y posteriormente decidieron invertir más capital en sus negocios por medio del micro crédito del programa Usura Cero. El 30.18\% empezaron sus negocios mediante capital propio y préstamos, comentaron que cuando decidieron invertir en un negocio no contaban con el suficiente capital propio y recurrieron a solicitar préstamos para poder hacer una inversión mayor. El $21.90 \%$ de los negocios iniciaron con préstamos de diferentes instituciones financieras o bien con el micro crédito del programa Usura Cero.

Actualmente $43.20 \%$ de los negocios operan con capital propio y créditos porque parte de la inversión que realizan en sus negocios es las misma utilidad que este les genera y solicitan créditos para complementar el dinero que disponen y poder hacer mayor compra de materiales o productos.

También en ocasiones la utilidad del negocio es destinada para gastos personales por lo que el $25.74 \%$ de las mujeres recurren a los créditos del Programa Usura Cero para invertir, comentan que con créditos pueden comprar gran parte de los productos necesarios para mantener surtidos sus negocios.

Sin embargo para el $33.43 \%$ de las mujeres estos créditos no son suficientes para la inversión total que les gustaría realizar, el $3.55 \%$ de los negocios funcionan con remesas enviadas ya sea del extranjero o desde otros ciudades el país y $2.07 \%$ funcionan con préstamos familiares.

El $66.57 \%$ de las mujeres afirma que el crédito facilitado por el Programa es suficiente para su inversión, sin embargo el $33.43 \%$ afirma lo contrario.

Actualmente el capital que las propietarias han invertido les ha permitido ver el incremento del negocio, comentan que han prosperado de gran 
manera en todo sentido ya sea en el aumento de clientes o bien a nivel personal, $97.93 \%$ de las 338 mujeres encuestadas estuvieron de acuerdo con que sus negocios han incrementado.

Tan solo $2.07 \%$ de las mujeres dicen que sus negocios no han incrementado por diferentes razones como que los plazos de crédito que otorgan a sus clientes es muy largo o los clientes toman más tiempo que el debido, además en ocasiones los préstamos solicitados no solo se destinan al negocio.

El $63.75 \%$ de los negocios ha tenido un incremento de 26 a $75 \%$ en su capital y utilidades, para ellas los microcréditos del programa usura cero han sido el factor principal del incremento en su negocio de igual manera un $28.09 \%$ de las mujeres indican que su negocio ha incrementado hasta un $25 \%$ probablemente porque gran cantidad de los negocios son más recientes de operar y $8.16 \%$ han tenido un incremento de 76 a $100 \%$ porque han realizado mayores inversiones.

\section{Tipo de inversiones realizadas}

Se refleja que el $45.26 \%$ de las propietarias de negocios indicaron que con las inversiones realizadas han comprado mercadería para surtir el negocio porque mientras más productos tengan para ofertar mayor es la utilidad que obtendrán. También cuando el local es atractivo la clientela se siente atraída al negocio por lo que el $23.27 \%$ de las mujeres han invertido en ampliar el local y tener espacio para almacenar más productos.

Un $14.49 \%$ han mejorado la infraestructura del negocio esto significa que sus hogares están en mejor estado porque la mayoría de los negocios se encuentran en locales propios o casas de habitación.

La publicidad juega un papel importante para conocer sobre los negocios porque aumenta la clientela por consiguiente las ganancias pero solo un $16.27 \%$ de las mujeres han decidido invertir en este. El 83.73\% no ha invertido en publicidad ya que sus negocios son pequeños y no venden a gran escala, además de que las ganancia no le permiten pagar por ese tipo de servicios también comentan que un buen servicio hacen mejor publicidad que cualquier otro medio.

En la encuesta se detallaron diversos medios de Publicidad tales como radio, rótulos periódico, televisión y perifoneo de los cuales únicamente radio y rótulos son utilizados como medio de publicidad, la radio con un $1.82 \%$, se utiliza este medio como una herramienta para la mejor divulgación del negocio y a través de este poder captar la atención de los clientes de toda la ciudad de Estelí y sus alrededores.

Los rótulos son utilizados en un $98.18 \%$ este medio es el favorito entre las mujeres que utilizan publicidad ya que es bajo en costos y lo pueden tener por un tiempo permanente.

\section{Captación de clientes}

También el crecimiento del negocio puede medirse por la nueva clientela que se ha acaparado, el $43.79 \%$ de las mujeres afirman que su clientela ha aumentado de 21 personas a mas porque con los créditos del Programa Usura Cero y sus ingresos han podido diversificar más los productos que ofrecen. De igual manera un $36.98 \%$ de las mujeres comentaron que ahora atienden de 11 a 20 personas más. El 2.07\% de las mujeres encuestadas dijeron que no atienden clientes nuevos pero aun así sus negocios han crecido porque los mismos clientes a los que atendían ahora compran en mayor cantidad sus productos.

Se reflejó que $61.83 \%$ de las microempresarias han decido conceder crédito a sus clientes porque para ellas aunque no es dinero al contado siguen siendo ventas además el crédito es otorgado a las personas con las sostienen amistad y porque tienen mucho tiempo siendo clientes habituales en sus negocios. El $38.17 \%$ de las mujeres prefirió ahorrarse la penosa 
cobranza y no otorgar crédito, pues al conceder crédito las utilidades tardan más tiempo en obtenerse e incluso en ocasiones no recuperan todo el monto de las deudas.

El $97.13 \%$ de las 209 mujeres que conceden crédito a sus clientes anotan en un cuaderno los registros de crédito para llevar al día las cuentas, incluso algunas propietarias han pedido a los clientes que lleven su registro en un cuaderno propio para conservar cuentas claras y no hayan confusiones. Tan solo $2.87 \%$ de las propietarias de negocios no anotan sus cuentas de crédito porque según ellas las llevan mentalmente lo cual es riesgoso porque pueden olvidarse del monto y confundirse de cliente.

El $59.33 \%$ de las propietarias que otorgan crédito a sus clientes no sobrepasan los 1,000 córdobas, $29.67 \%$ de las mujeres otorgan como monto máximo 500 córdobas y tan solo $3.35 \%$ conceden créditos que exceden los 2,001 córdobas pero para ellas son clientes confiables.

\section{Administración y contabilidad del negocio}

El $63.61 \%$ de los negocios no llevan una contabilidad formal. El $44.37 \%$ de las mujeres encuestadas no llevan contabilidad en su negocio porque no saben de qué manera llevar un registro de ingresos y egreso. Por otra parte el $30.43 \%$ no considera importante llevar un registro, manejan sus ingresos y egresos de manera mental lo cual es riesgoso porque tienden a haber confusiones.

El $18.64 \%$ opino que su negocio es pequeño por lo tanto según ellas no es necesario llevar contabilidad formal. Mientras un $8.87 \%$ comentaban que la razón para no llevar contabilidad formal en sus negocios es que no tienen tiempo para registrar sus ventas y sus gastos diarios pues sus negocios se mantienen en movimiento lo que les impide registrar correctamente sus cuentas.
El $56.80 \%$ de las mujeres tienen metas de ventas ya que se plantean un desarrollo y ampliación de sus negocios, además piensan en realizar mejoras en la infraestructura y compra de mobiliario que necesitan dentro de sus negocios además se establecen un estimado de cuanto venden al mes especialmente las mujeres que tienen negocio de comiderías o fritangas. Tan solo el $43.20 \%$ no tiene metas de ventas ya que se sienten conforme con los resultados que dan sus negocios.

El $55.33 \%$ de las mujeres llevan un control de inventario ya que una de sus prioridades es que no exista escases de materia prima para no dejar de producir o vender. Un $44.67 \%$ no lleva un control de inventario porque en algunos de los negocios, no venden o producen en grandes cantidades, algunos de los negocios son pequeños por lo cual no se decide llevar un control.

El $77.22 \%$ de las mujeres tienen las posibilidades de realizar sus compras en efectivo ya que las utilidades que obtienen con su negocio son suficientes para realizarlas de esta manera. Un $11.54 \%$ realiza sus compras combinando sus utilidades y créditos ya que los ingresos no son suficientes para comprar todos los productos que necesitan para mantener surtido y funcionando su negocio. Un $11.24 \%$ obtiene al crédito su mercadería debido a que la mayoría de las dueñas de negocios brindan crédito a sus clientes y en ocasiones no pagan en tiempo y forma y se necesita reabastecer el negocio, lo que dificulta tener un capital en efectivo para la realización de las compras.

\section{CONCLUSIONES}

El financiamiento del crédito del Programa Usura Cero ha generado un cambio positivo en el nivel de vida de las microempresarias creadoras de MIPYMES de la ciudad de Estelí, ingresar al programa ha sido ventajoso pues mediante las capacitaciones brindadas por los técnicos del programa han adquirido conocimientos 
que han puesto en práctica en sus negocios esto ha sido de gran utilidad ya que llevan un registro claro y ordenado de los ingresos y egresos.

Cabe mencionar que el $63.61 \%$ de las beneficiadas no emplean contabilidad formal en sus negocios esto tiende a ser una debilidad ya que no tienen ningún documento que respalde las actividades financieras realizadas en los mismos, uno de los principales factores de no llevar contabilidad formal es debido a que los negocios son pequeños por lo tanto no consideran necesario hacer uso de un sistema contable.

Existen debilidades en el crecimiento de los negocios debido a que algunas de las mujeres beneficiadas hacen mal uso del préstamo, no utilizan el crédito para invertirlo en sus negocios según las palabras de la Lic. Teresa Cruz responsable del Programa Usura Cero en la ciudad de Estelí, quien se encarga de verificar que el crédito sea utilizado para lo que es financiado.

La hipótesis se ha cumplido al verificar que el financiamiento del Programa Usura Cero si ha influido en el desarrollo económico de las MIPYMES creadas por las beneficiadas; el $56.80 \%$ de las mujeres expreso haber ampliado su negocio, mejorado sus ingresos familiares, obtenido independencia económica y enriquecido conocimientos administrativos y de control financiero.

Es importante hacer mención que el programa hasta el momento ha cumplido con su objetivo principal; el cual es la restitución de los derechos de las mujeres las cuales están siendo partícipes del desarrollo económico de la ciudad y por consiguiente del país al obtener los microcréditos del Programa Usura Cero e invertirlos en sus negocios.

\section{RECOMENDACIONES}

Para que esta investigación sea de utilidad a propietarias de MIPYMES, autoridades, personal docente y estudiantil de la Facultad Regional Multidisciplinaria así como personas ajenas a la misma y al personal que dirige el Programa Usura Cero; se recomienda:

- A las propietarias de MIPYMES Asistir de manera puntual y consecutiva a todas las capacitaciones brindadas por el Programa Usura Cero y que implementen en sus negocios los conocimientos adquiridos en las mismas con el fin de solidificarse como microempresarias de la ciudad de Estelí.

- Al personal que dirige el Programa Usura Cero que se involucren más en el funcionamiento de los negocios de las mujeres y de esta manera conocer las debilidades que los negocios presentan para incorporar dichas debilidades en temas de capacitación.

- A personal docente y estudiantil de la Facultad Regional Multidisciplinaria promover la capacidad investigativa desde el inicio de las carreras para facilitar la realización de futuras investigaciones, además que los estudiantes hagan uso de previas investigaciones con el fin de lograr realizar documentos de calidad.

- A personas ajenas a la Facultad Regional Multidisciplinaria que tomen como una herramienta útil las investigaciones y/o documentos que se encuentran en la biblioteca "Urania Zelaya", facilitándoles así la realización de investigaciones propias, además encontrar en estas una fuente de información.

\section{BIBLIOGRAFIA}

Rodríguez Valencia, J.(2002) Administración de pequeñas y medianas empresas. Ed CengageLearning II Edición.

Gitman, L. (2007) Principios de Administración 
financiera, pág. 526. Pearson education, México. XI Edición.

Ley de Promoción, Fomento y Desarrollo de la micro, pequeña y mediana Empresa. Ley MIPYME (2005) Arto. 32. Registro Único de las MIPYMES.

Cuadra, S. Maestría en Administración y Dirección de Empresas (MADE) Facultad de ciencias Económicas y Empresariales de la UCA. Apdo. 69, Managua- Nicaragua. 